\title{
Developing a Dalhousie satellite undergraduate medical education program to meet the needs of New Brunswick
}

$\mathrm{T}$ he Faculty of Medicine at Dalhousie University has recently been approached by the Government of New Brunswick to develop a proposal for the delivery of Dalhousie's four-year undergraduate medical education program in New Brunswick. There is now considerable evidence that physicians are more likely to choose to practice in a community in which a significant portion of their medical training has occurred. New Brunswick currently has one of the lowest ratios of physicians to population in Canada and in response to this, the New Brunswick Government is seeking ways to increase the opportunities for medical students to receive their medical education in New Brunswick.

Dalhousie has a long history of both postgraduate and undergraduate medical education in the province of New Brunswick. Indeed, a Dalhousie Internship Program was developed at the Saint John General Hospital during the 1920's and there have been Dalhousie students, interns and/or residents training in the province of New Brunswick almost continually since then. Currently in New Brunswick, over 90 medical students complete over 600 weeks of rotations while almost 210 residents complete over 3,700 weeks of rotations at various sites in the province. Many Dalhousie Family Medicine residents complete their entire postgraduate training in New Brunswick.

Recently it has become increasingly apparent that physician shortages exist and almost certainly will get worse over the coming years. In addition to what appears to be an inadequate number of physicians in many areas, there are also concerns regarding the distribution of physicians, with many non-urban areas of the country finding it difficulty to recruit and/or retain an adequate number of practicing physicians. Atlantic Canada is no exception to this phenomenon. In response to this challenge, New Brunswick is developing a Moncton based Francophone undergraduate medical education program in collaboration with the University of Sherbrooke. In the Fall of 2005, Premier Lord announced that there will also be an Anglophone undergraduate medical education program associated with an existing medical school which will be distributed in the four major Anglophone regions of the province (Saint John, Fredericton, Moncton and Miramichi). The New Brunswick request of Dalhousie to develop an undergraduate medical education program in the province is a result of Premier Lord's announcement.

Developing a successful satellite undergraduate medical education program is an enormous undertaking, which obviously requires a huge amount of planning as well as adequate resources. A planning task force of representatives from both Dalhousie Faculty of Medicine and New Brunswick has just been struck to develop a preliminary planning proposal which must be submitted to the Government of New Brunswick by June 30, 2006, an exceedingly short time frame. The planning group includes the author, Susan Spence Wach (Associated Dean, Health Systems and Policy), Sam Rowe (Associate Dean, Undergraduate Medical Education), Karen Mann (Director, Division of Medical Education), Bruce Holmes (Executive Director, Learning Resource Centre) from Dalhousie as well as Lyne Ste-Pierre-Ellis (Director, Health Workforce Planning and Physician Resources Advisor, New Brunswick Department of Health), John Steeves (Director of Medical Education, Atlantic Health Sciences Centre), Preston Smith (Program Director, Northumberland and Family Medicine Teaching Unit), Pascal Robichaud (New Brunswick Department of Post-Secondary Education and Training) and Deborah McLatchy (Dean of Science and Applied Science \& Engineering, University of New Brunswick at Saint John).

The task force will develop a high-level proposal outlining the basic requirements for a subsequent detailed planning process which will be necessary before students can be admitted to a four year Dalhousie undergraduate program in New Brunswick. Planning will be based on a number of important principles, which include:

- The quality of medical education in New Bruns- 
wick must be equal to or exceed that delivered in Halifax.

- The entire Dalhousie undergraduate program in all sites must meet all accreditation requirements and standards.

- New Brunswick students will be admitted to the Dalhousie Faculty of Medicine and will receive their medical degree from Dalhousie University; there will be appropriate meaningful representation from New Brunswick in the selection of students in the New Brunswick cohort.

- The development of a four year undergraduate program in New Brunswick must not disrupt or negatively impact the existing postgraduate medical education programs in New Brunswick.

The initial planning will be for up to 30 students who will receive all four years of their undergraduate medical education in New Brunswick with the first two years sited primarily in Saint John and the final two

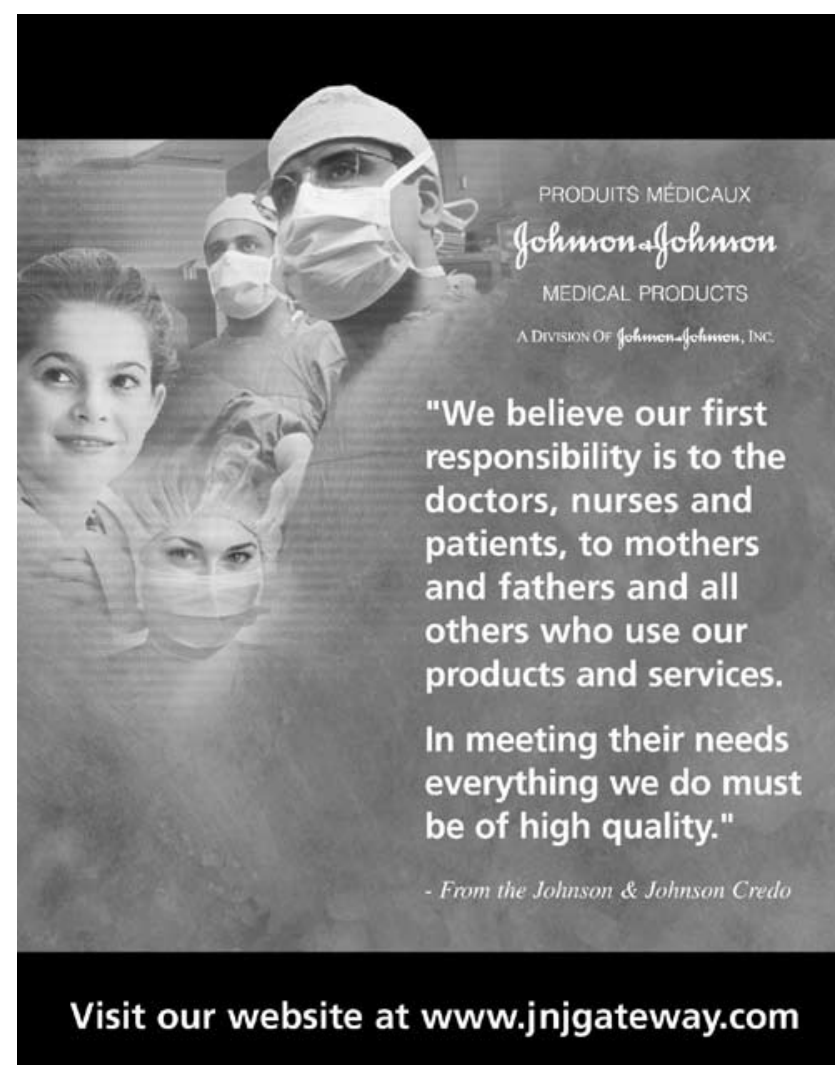

clinical years distributed among the four Anglophone regions. In order to develop an excellent program, considerable time and resources will be required to properly plan and implement this ambitious medical education vision. Wide consultation with faculty and students at Dalhousie and colleagues in New Brunswick will occur during the detailed planning process which is expected to begin some time after the initial proposal document is submitted to the New Brunswick government at the end of June 2006.

The development of a Dalhousie four-year medical education program in New Brunswick is an exciting opportunity to enhance medical education in Maritime Canada and to better meet the health care needs of Maritime Canadians.

\section{Jonathan Kronick}

Head/Chief, Department of Pediatrics, Dalhousie University/IWK Health Centre Assistant Dean, Regional Medical Education 